\title{
Improvement of physicochemical parameters of acyclovir using cocrystallization approach
}

\author{
Jignasa Ketan Savjani", Chirag Pathak
}

Institute of Pharmacy, Nirma University, Ahmedabad, Gujarat, India

\begin{abstract}
Acyclovir is an antiviral drug having potent activity against the virus of herpes family and varicella zoster. Unfortunately, drug suffers very poor oral bioavailability (15-30\%). The main objective of present study was to develop acyclovir cocrystals with improved solubility which may result in improvement of bioavailability. Hansen solubility approach was used as a tool to predict the cocrystal formation of a drug with selected coformer. Cocrystals of acyclovir with various coformers were screened in order to enhance their water solubility. Cocrystals of the drug were prepared using various methods like solvent evaporation, wet grinding, and antisolvent addition. Formation of cocrystals by solvent evaporation method was found to be better method amongst all. Optimization of cocrystal formation was carried out by employing different solvents as well as the stoichiometric ratio of acyclovir with that of coformer. Synthesis of cocrystals was optimized using water as a solvent system resulted in good agreements. The potential cocrystal formation of acyclovir was characterized by IR, PXRD and DSC techniques. An in-vitro dissolution study was performed to determine the dissolution rate of cocrystals. The results suggest that acyclovir forms cocrystals with tartaric acid and the initial dissolution rate of synthesized cocrystals were considerably faster as compared to pure acyclovir.
\end{abstract}

Uniterms: Acyclovir/study. Acyclovir/dissolution study. Cocrystal/technique. Hansen solubility parameters. Solvent evaporation method.

\section{INTRODUCTION}

Active Pharmaceutical Ingredients (APIs) are commonly administered in the solid dosage form as it is the convenient formulation. Drug molecules can exist in a variety of different solid forms, where each form may display unique physicochemical properties such as hygroscopicity, morphology and most importantly solubility. Unfortunately, many potentially useful compounds with highly desirable molecular pharmacological properties may never realize their maximum potential because the physical properties of the compound display unfavorable bioavailability and unacceptable shelf life (Aakeröy, Fasulo, Desper, 2007). Though numerous strategies like formation of salts, solvates, hydrates etc. exist for enhancing the bioavailability of drugs. However, these approaches depend on the physicochemical properties of the considered

\footnotetext{
*Correspondence: J. K. Savjani. Institute of Pharmacy. Nirma University. 382481 - S.G.Highway, Ahmedabad, Gujarat, India. Phone: +91-9824550737. E-mail: jignasasavjani@gmail.com
}

molecules, which hampers widespread application (Khan, Enkelmann, Brunklaus, 2010).

Indeed, it is well known that fundamental properties of (crystalline) materials originate from molecular arrangements within the solid (Stahly, 2007). Altering the chemical structure of the molecules typically has a direct impact on the properties of the particular solid. In addition to these established crystalline API modifications, pharmaceutical cocrystals, or crystalline molecular complexes involving an API, have recently attracted interest as an alternative approach (Dunitz, 2007). A cocrystal may be thought of as a crystalline complex of two or more neutral molecular constituents bound together in the crystal lattice through noncovalent interactions, often including hydrogen bonding (Jones, Motherwell, Trask, 2006; Aakeröy, Desper, Fasulo, 2006). Pepinsky and Schmidt discovered crystal engineering, which is similar to supramolecular synthesis in the solid state. Crystal engineering is the technique to generate new compounds through self-assembly, instead of using traditional multistep covalent synthesis (Bis et al., 2007). Modification of the physicochemical properties of 
APIs could be achieved using pharmaceutical cocrystal approach instead of salt formation, and polymorphic and amorphous forms, that all have limitations in their utility (Masuda et al., 2012).

Acyclovir (CID 2022) is one of the most commonly used antiviral drug used in the treatment of herpes simplex viral infections. It is also used for the management of the disease caused by varicella zoster (chickenpox) and herpes zoster (shingles) viruses (Balfour, 1993). Various scientific researches in the pharmaceutics have proved acyclovir as a potent drug for the above mentioned physiological infections. Acyclovir is currently marketed as capsules, tablets, suspensions for oral administration. Over the half of the dose of currently marketed formulation is recovered in the feces Susantakumar, Gaur, Sharma (2011). Failure to respond to acyclovir therapy may arise due to poor aqueous solubility. Previously to improve the solubility, the preparation of a solid dispersion, an inclusion complex and a microemulsion of acyclovir were reported (Patel, Sawant, 2007; Sachan et al., 2010; Rossel et al., 2000). However, the liquid formulations suffer from the problems of stability issues and are not convenient to administer. Cocrystals of acyclovir with 1-tartaric acid were reported to improve the physical properties of the drug; whereby cocrystals were prepared using dimethylformamide and acetic acid as solvents (Masuda et al., 2012).

Thus, the development of the readily absorbed oral antiviral drug is an unmet need for the viral disease. Previous attempts have been made to improve the bioavailability of acyclovir by formulating waterdispersible tablets which facilitate to incorporate higher dose; up to $800 \mathrm{mg}$. The tablet, however, does not improve the bioavailability of the drug. Acyclovir sodium is available as a powder for injection or intravenous infusion in dosages of 25 and $50 \mathrm{mg} / \mathrm{mL}$. The solubility of acyclovir sodium salt is more than $100 \mathrm{mg} / \mathrm{mL}$ at 25 ${ }^{\circ} \mathrm{C}$ in water but at $\mathrm{pH} 7.4$ and $37{ }^{\circ} \mathrm{C}$, the drug is almost completely unionized and has a maximum solubility of $2.5 \mathrm{mg} / \mathrm{mL}$ (Bethesda, 1997). In patients with renal impairment, acyclovir is associated with neurotoxicity when administered with intravenous route, but if given orally, the doses are typically low and serious adverse effects are extremely rare (Tilson, Engle, Andrews, 1993).

Acyclovir exists in four anhydrous forms and two hydrated forms (Kristl et al., 1996; Lutker et al., 2011; Bruni et al., 2013). The hydrated and anhydrated forms of acyclovir reported till now suffered from poor water solubility (Kristl et al., 1996). According to different Pharmacopoeias, acyclovir is "slightly solubility in water" at $22-25^{\circ} \mathrm{C}$ and solubility ranges from 1.2 to 1.6 $\mathrm{mg} / \mathrm{mL}$. The solubility of the drug varies slightly with $\mathrm{pH}$ and lowest solubility of $2.3 \mathrm{mg} / \mathrm{mL}$ reported at $\mathrm{pH}$ 5.8 at $37{ }^{\circ} \mathrm{C}$ (Luengo et al., 2002, Susantakumar, Gaur, Sharma, 2011).

The aim of the study was to prepare cocrystals of acyclovir with different coformers (Figure 1). For the said purpose, first Hansen Solubility Parameters (HSPs) approach was used to investigate the miscibility of a drug and coformer. To predict the miscibility of a drug with excipients in different formulation like solid dispersions, HSPs have been widely used (Greenhalgh et al., 1999). HSPs could predict the compatibility of pharmaceutical materials and for pre-formulation and formulation development of tablets. The HSPs of the coformers and acyclovir were calculated using group contribution methods. Based on the HSPs calculations, coformers were selected for cocrystallization with acyclovir (Mohammad, Alhalaweh, Velaga, 2011).

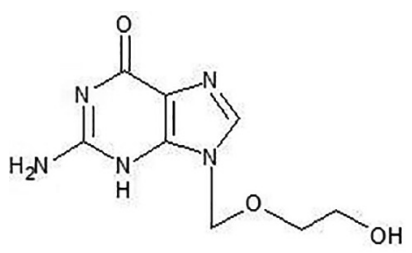

Aciclovir

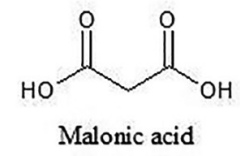<smiles>O=C(O)C(O)C(O)C(=O)O</smiles>

Tartaric acid

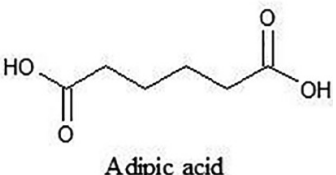

FIGURE 1 - Chemical structure of acyclovir and coformers used in the study.

\section{MATERIALS AND METHODS}

\section{Materials}

Acyclovir was donated by Cadila Healthcare (Zydus), Ahmedabad. Coformers and Other reagents were purchased from S.d Fine Chem Ltd.

\section{Methods}

\section{HSPs calculations of Acyclovir}

The group contribution method was employed to calculate HSPs of the acyclovir which only requires knowledge of the compound's chemical structure. According to HSPs, the total force of the various interactions can be divided into partial solubility 
parameters, i.e. dispersion $\left(\delta_{\mathrm{d}}\right)$, Polar $\left(\delta_{\mathrm{p}}\right)$ and hydrogen bonding $\left(\delta_{\mathrm{h}}\right)$ (Fedors, 1974; Van Krevelen, 1990).

Van Krevelen-Hoftyzer and Fedors combined group contribution methods were used to calculate the partial solubility parameters for acyclovir and different coformers. Compounds with similar $\delta$ values are likely to be miscible (Özdemir, Güner 2007).

$$
\begin{gathered}
\delta_{\mathrm{d}}=\Sigma \mathrm{F}_{\mathrm{di}} / \Sigma \mathrm{V}_{\mathrm{i}} \\
\delta_{\mathrm{P}}=\left(\Sigma \mathrm{F}_{\mathrm{Pi}}^{2}\right)^{1 / 2} / \Sigma \mathrm{V}_{\mathrm{i}} \\
\delta_{\mathrm{h}}=\left(\Sigma \mathrm{F}_{\mathrm{hi}} / \Sigma \mathrm{V}_{\mathrm{i}}\right)^{1 / 2} \\
\delta_{\mathrm{t}}=\left(\delta_{\mathrm{d}}^{2}+\delta_{\mathrm{p}}^{2}+\delta_{\mathrm{h}}{ }^{2}\right)^{1 / 2} \\
\delta_{\mathrm{v}}=\left(\delta_{\mathrm{d}}^{2}+\delta_{\mathrm{p}}^{2}\right)^{1 / 2}
\end{gathered}
$$

where $\mathrm{i}$ is the structural group within the molecule, $\mathrm{F}_{\mathrm{di}}$ is the group contribution to the dispersion forces, $\mathrm{F}_{\mathrm{pi}}$ is the group contribution to the polar forces, $\mathrm{F}_{\mathrm{hi}}$ is the group contribution to the hydrogen bonding energy, $\mathrm{V}_{\mathrm{i}}$ is the group contribution to the molar volume.

Different approaches were used to estimate the miscibility of compounds as discussed by Mohammad, Alhalaweh, Velaga (2011) The miscibility of two compounds $(\Delta \delta)$ can be calculated using the following equation given by Van Krevelen and Hoftyzer (Alhalaweh, Alzghoul, Kaialy, 2014). Good miscibility can be achieved if $\Delta \delta \leq 5 \mathrm{MP}^{0.5}$ (Guner, 2004).

$$
\Delta \delta=\left[\left(\delta_{\mathrm{d} 2}-\delta_{\mathrm{d} 1}\right)^{2}+\left[\left(\delta_{\mathrm{p} 2}-\delta_{\mathrm{p} 1}\right)^{2}+\left[\left(\delta_{\mathrm{h} 2}-\delta_{\mathrm{h} 1}\right)^{2}\right]^{1 / 2}\right.\right.
$$

The effects of $\delta_{\mathrm{d}}$ and $\delta_{\mathrm{p}}$ are thermodynamically similar, and the effect of $\delta_{\mathrm{h}}$ is different in nature. So volume dependent solubility parameter was calculated by using following equation (Maniruzzaman et al., 2013).

$$
\delta_{\mathrm{v}}=\left(\delta_{\mathrm{d}}^{2}+\delta_{\mathrm{p}}^{2}\right)^{1 / 2}
$$

Prediction of miscibility between two compounds can also be determined by $\mathrm{R}_{\mathrm{a}(\mathrm{v})}$ factor.

$$
\mathrm{R}_{\mathrm{a}(\mathrm{v})}=\left[4\left(\delta_{\mathrm{v} 2}-\delta_{\mathrm{v} 1}\right)^{2}+\left(\delta_{\mathrm{h} 2}-\delta_{\mathrm{h} 1}\right)^{2}\right]^{1 / 2}
$$

Two components are likely to be miscible if $\mathrm{R}_{\mathrm{a}(\mathrm{v})} \leq$ $5.6 \mathrm{MP}^{0.5}$ as reported by Mohammad, Alhalaweh, Velaga (2011).

Total solubility parameter $\left(\Delta \delta_{t}\right)$ between the drug and the carriers can be applied as a tool to predict the miscibility of two compounds.

$$
\Delta \delta_{\mathrm{t}}=\left|\delta_{\mathrm{t} 2}-\delta_{\mathrm{t} 1}\right|
$$

where $\mathrm{t} 1$ and $\mathrm{t} 2$ are carriers and drug respectively and compounds with $\Delta \delta_{\mathrm{t}}<7 \mathrm{MP}^{0.5}$ are miscible with each other (Mohammad, Alhalaweh, Velaga, 2011).

\section{Preparation of acyclovir cocrystals}

Synthesis of cocrystals of acyclovir was carried out using various methods like solvent evaporation, wet grinding, and antisolvent addition. Screening of cocrystal formation was carried out by employing different coformers in optimum molar ratio with that of acyclovir using different solvents (Karki et al., 2007).

\section{Cocrystallization of acyclovir-tartaric acid}

A 1:6 mixture of acyclovir and tartaric acid was dissolved in water and stirred continuously at $70{ }^{\circ} \mathrm{C}$. After 30 minutes remaining solvent was evaporated to $3 / 4^{\text {th }}$ of its volume at $70^{\circ} \mathrm{C}$ and transferred immediately to the cold environment i.e. $0^{\circ} \mathrm{C}$. Obtained crystals were filtered and dried in a desiccator over silica gel at room temperature.

\section{Characterization of Cocrystal formation}

Formation of cocrystals was primarily confirmed by comparing the melting points (Scientific MP1) of cocrystal with that of pure drug and respective coformer.

The shape of cocrystals was compared with the pure drug and coformer using microscopic inspection (LYNX XSP-35) as a primary evaluation parameter.

\section{Infra Red spectroscopy}

IR spectra of samples were recorded on FT/IR-6100 (JASCO Corporation, Tokyo, Japan) by KBr dispersion method. The spectra were collected over the range of $4000-1000 \mathrm{~cm}^{-1}$ in 32 scans, with a resolution of $4 \mathrm{~cm}^{-1}$ for each sample.

\section{Differential Scanning Calorimetry}

DCS technique was used to identify the difference in the amount of heat required to increase the temperature of a sample as a function of temperature. The samples were analyzed by Differential Scanning Calorimeter (DSC-60) over the range of $50-300^{\circ} \mathrm{C}$ at the rate of $20^{\circ} \mathrm{C}$ per minute.

\section{Powder X-ray diffractometry (PXRD)}

$X$-ray powder diffraction of the synthesized cocrystals was collected using spinner PW3064 at the minimum step size 2Theta:0.001 and minimum step size Omega: 0.001.

\section{In vitro dissolution study}

The in vitro dissolution assay was performed to check the dissolution rate of cocrystals initially in 
triplicate (Kadu et al. 2011). $50 \mathrm{mg}$ of each acyclovir and cocrystals were used to carry out the dissolution study using dissolution test apparatus (basket method). The dissolution was carried out by taking medium consisted of $900 \mathrm{~mL}$ of phosphate buffer at $\mathrm{pH} 6.8$ equilibrated at $37^{\circ} \mathrm{C} \pm 0.5^{\circ} \mathrm{C}$ with a stirring speed of 50 rotations per minute. At definite time interval, $10 \mathrm{~mL}$ of solution was withdrawn to measure the absorbance and $10 \mathrm{~mL}$ of fresh dissolution medium was added to maintain the volume. Aliquots withdrawn were analyzed under UV spectrophotometer to check the absorbance at $255 \mathrm{~nm}$. The dissolution study carried out up to 1 hour. To convert the absorbance of the samples in terms of concentration of the drug, a standard curve of the pure drug acyclovir was obtained (Doile et al., 2008).

\section{RESULTS AND DISCUSSION}

\section{Miscibility prediction of coformers with acyclovir using HSPs method}

A diverse set of thirty-four coformer with the ability to form hydrogen bonds with acyclovir were used in the study. The HSPs calculations of acyclovir are summarized in Table I as an example using the group contribution method following the combined models of Fedors and Van Krevelen-Hoftyzer. The HSPs calculations of acyclovir and the coformers were carried out using Van Krevelen-Hoftyzer, Bagley and Greenhalgh methods to study miscibility of two components (Greenhalgh et al., 1999; Van Krevelen, 1990).

TABLE I - HSPs and molar volume calculations for acyclovir according to the Hoftyer-Van Krevelen method<smiles>Nc1nc(=O)c2ncn(COCCO)c2[nH]1</smiles>

\begin{tabular}{|c|c|c|c|c|c|}
\hline Group & Frequency & $\mathrm{F}_{\mathrm{di}}\left(\mathrm{J}^{1 / 2} \mathrm{~cm}^{3 / 2} \mathrm{~mol}^{-1}\right)$ & $\mathrm{F}_{\mathrm{pi}}\left(\mathrm{J}^{1 / 2} \mathrm{~cm}^{3 / 2} \mathrm{~mol}^{-1}\right)$ & $\mathrm{F}_{\mathrm{hi}}\left(\mathrm{J}^{1 / 2} \mathrm{~cm}^{3 / 2} \mathrm{~mol}^{-1}\right)$ & $\mathrm{V}\left(\mathrm{cm}^{3} \mathrm{~mol}^{-1}\right)$ \\
\hline$-\mathrm{NH}_{2}$ & 1 & 280 & 0 & 8400 & 19.2 \\
\hline$-\mathrm{NH}$ & 1 & 160 & 210 & 3100 & 4.5 \\
\hline$\rangle=0$ & 1 & 290 & 770 & 2000 & 10.8 \\
\hline$-\mathrm{CH}_{2}-$ & 3 & $270 \times 3=810$ & 0 & 0 & $16.1 \times 3=48.3$ \\
\hline$-\mathrm{O}-$ & 1 & 100 & 400 & 3000 & 3.8 \\
\hline$-\mathrm{OH}$ & 1 & 210 & 500 & 20,000 & 10.0 \\
\hline$-\mathrm{N}$ & 2 & $20 \times 2=40$ & 800 & 5000 & $5.0 \times 2=10$ \\
\hline & 1 & 20 & 800 & 5000 & -9.0 \\
\hline$=\mathrm{CH}-$ & 1 & 200 & 0 & 0 & 13.5 \\
\hline & 3 & 210 & 0 & 0 & -16.5 \\
\hline Ring & 2 & $190 \times 2=380$ & 0 & 0 & $16 \times 2=32$ \\
\hline \multirow{2}{*}{$\begin{array}{l}\text { Conjugation in Ring } \\
\text { for each double bond }\end{array}$} & 3 & - & - & - & $-2.2 \times 3=-6.6$ \\
\hline & & & & & 135.6 \\
\hline
\end{tabular}


From correlation plots of $\delta_{\mathrm{h} 2}-\delta_{\mathrm{h} 1}, \delta_{\mathrm{p} 2}-\delta_{\mathrm{p} 1}$ and $\delta_{\mathrm{d} 2}$ $-\delta_{\mathrm{d} 1}$ Vs $\Delta \delta$, it was observed that $\delta_{\mathrm{h} 2}-\delta_{\mathrm{h} 1}$ correlated well with $\Delta \delta$ as the correlation coefficient was found to be 0.939 . The results of correlation plot indicate contribution of hydrogen bonding for miscibility of two components.

According to the criterion of Greenhalgh et al. (1999) (i.e. $\Delta \delta_{t}<7 \mathrm{MP}^{0.5}$ ) eighteen out of thirty-two coformers were predicted to be miscible with acyclovir. The predicted values for miscibility of compounds possessing carboxylic acid as a functional group was found to be satisfactory as coformers with drug according to the criterion of Bagley et al. (1971), Greenhalgh et al. (1999), and Van Krevelen (1990) and Hoftyzer for $\Delta \delta_{t}, \Delta \delta$ and
$\mathrm{R}_{\mathrm{a}(\mathrm{v})}$. The predicted miscibility of the selected coformers (Table II) with the drug was also verified experimentally in triplicate.

\section{Cocrystals screening and physical characterization}

Synthesis of cocrystals of acyclovir with coformer using methods like solvent evaporation, wet grinding, and an anti-solvent addition was carried out. Optimization of synthesis of cocrystals was performed by utilizing various solvents like ethanol, ethyl acetate, acetone, water and isopropyl alcohol as summarized in Table III.

TABLE II - Physical properties of cocrystal formers

\begin{tabular}{lccc}
\hline Coformers & Pub Chem ID & Molecular weight $(\mathrm{g} / \mathrm{mol})$ & Melting point $\left({ }^{\circ} \mathrm{C}\right)$ \\
\hline Tartaric acid & CID 875 & 150 & 171 \\
Succinic acid & CID 1110 & 118.09 & 185 \\
Malonic acid & CID 867 & 104.06 & 135 \\
Glutaric acid & CID 743 & 132.12 & 95 \\
Adipic acid & CID 196 & 146.14 & 152 \\
Citric acid & CID 311 & 192.12 & 156 \\
4-amino benzamide & CID 76079 & 136.15 & 181 \\
4-hydroxy benzamide & CID 65052 & 137.14 & 161 \\
4-amino benzoic acid & CID 978 & 137.14 & 187 \\
Malic acid & CID 525 & 134.87 & 130 \\
Oxalic acid & CID 971 & 126.08 & 102 \\
Fumaric acid & CID 444972 & 116.07 & 287 \\
\hline
\end{tabular}

TABLE III - Screening of cocrystal formation using different solvents

\begin{tabular}{lccccc}
\hline Cocrystal former & Water & Ethanol & Acetone & Ethyl acetate & Isopropyl alcohol \\
\hline Tartaric acid & ACC & DF & PM & PM & PM \\
Succinic acid & DF & DF & NT & NT & NT \\
Malonic acid & ACC & DF & DF & DF & PM \\
Glutaric acid & DF & DF & NT & NT & NT \\
Adipic acid & ACC & DF & DF & DF & PM \\
Citric acid & DF & DF & PM & PM & NT \\
4-amino benzamide & PM & DF & NT & PM & NT \\
4-hydroxy benzamide & PM & NT & NT & NT & NT \\
4-amino benzoic acid & PM & NT & NT & NT & NT \\
Malic acid & DF & DF & PM & NT & NT \\
Oxalic acid & DF & DF & PM & NT & NT \\
Fumaric acid & DF & Cocrystals* & DF & DF & DF \\
\hline ACC: Acycorid
\end{tabular}

ACC: Acyclovir cocrystals, DF: Different crystal form or non-uniform crystals, PM: Physical Mixture, (NT) Experiment not conducted, Cocrystals*: Not reproducible 
It was observed that using ethanol as a solvent for cocrystallization suffered the early precipitation of the acyclovir, which was confirmed by microscopic inspection indicated non-uniform shape of crystals. The synthesis of cocrystal was optimized using water as a solvent as it is clean, cheap and ultimate solvent for replacing the traditional polar aprotic solvents. As the water is used throughout the process, it claims the green chemistry approach for the synthesis of cocrystals.

Solvent evaporation using water as a solvent gave the satisfactory results for the formation of cocrystals of acyclovir. Preliminary evaluation of formation of cocrystals was carried out by comparison of melting points of pure drug, coformers, and cocrystals.

The shape of synthesized cocrystals was observed under the microscope for their uniformity and crystal habit. Microscopy study revealed the formation of cocrystal with glutaric acid not showing a comparable difference in the crystal shape with that of pure glutaric acid. While the formation of cocrystals with tartaric acid, succinic acid, malonic acid and adipic acid exhibited good results.

Different methods were used for the synthesis of cocrystals of acyclovir. Solvent evaporation method was found to be a more efficient method for cocrystallization.

Acyclovir has 3 hydrogen bond donor and 4 hydrogen bond acceptor sites for the formation of the hydrogen bond with coformer. The ratio of coformer with that of acyclovir was optimized for the formation of cocrystals.

A stoichiometric amount of acyclovir and coformer was taken for cocrystal synthesis by solvent evaporation method. Cocrystallization of a drug with selected coformer in a ratio of 1:6 (acyclovir:cocrystal former) afforded cocrystal formation.

Differential Scanning Calorimetry (DSC) was performed for the pure drug acyclovir (Rajurkar, Gite, Ghawate, 2015), coformer and synthesized cocrystals over the range of $50-300{ }^{\circ} \mathrm{C}$ at the rate of $20^{\circ} \mathrm{C}$ per minute. DSC peak of CA1 (acyclovir+tartaric acid), CA3 (acyclovir+malonic acid) and CA5 (acyclovir+adipic acid) was different as compared to pure drug and coformer suggested the formation of new solid phase.

PXRD diffractogram of cocrystals of acyclovir with tartaric acid as compared to pure drug and coformer resembled completely new patterns indicating generation of new solid forms. PXRD patterns of CA3 and CA5 suggested the physical mixture of acyclovir with coformers, although a single distinguish DSC peak obtained as compared to acyclovir and respective coformers. DSC analysis and PXRD patterns revealed the formation of cocrystals of acyclovir with tartaric acid as shown in Figures 2 and 3.

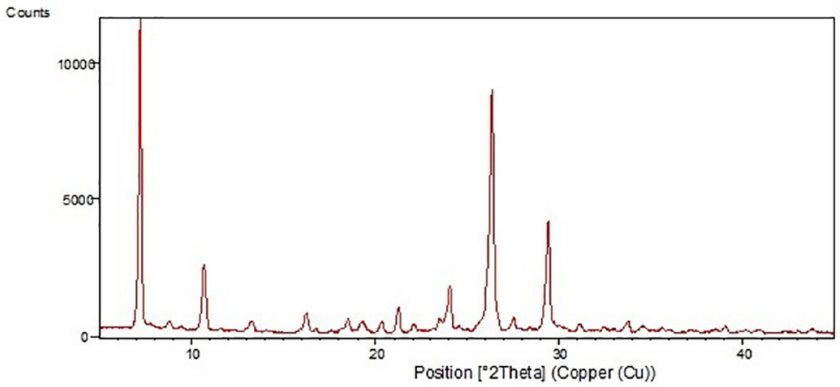

FIGURE 2 - PXRD patterns of acyclovir.

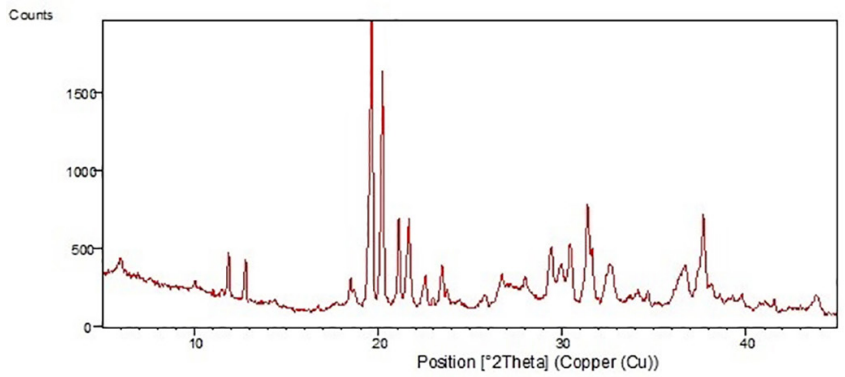

FIGURE 3 - PXRD patterns of CA1 (Acyclovir : Tartaric acid $(1: 6))$.

\section{In vitro dissolution assay}

Synthesized cocrystals were evaluated by in-vitro dissolution assay. Cumulative $\%$ drug release of synthesized cocrystals was obtained by dissolution study and was compared with that of pure API. One hour dissolution study was performed for both pure acyclovir and cocrystals. A standard curve of acyclovir is shown in Figure 4.

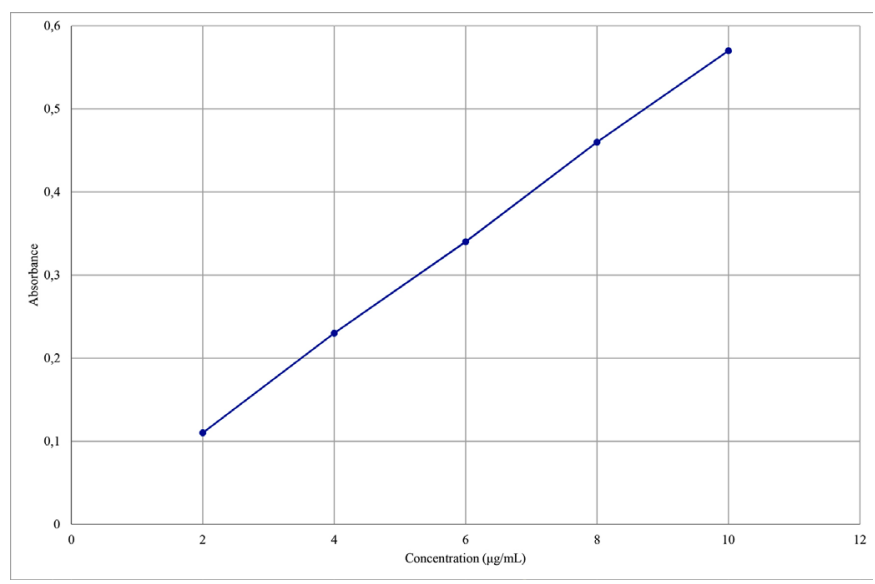

FIGURE 4 - Standard curve of acyclovir.

The final results were obtained in terms of cumulative $\%$ drug release. Significant increase in the cumulative $\%$ drug release was observed for cocrystals as compared to acyclovir. From dissolution study, it was observed that 
after 1 min pure acyclovir showed the release of $6.82 \%$ into the medium. While CA1 showed much higher drug release of $26.69 \%$ as compared to acyclovir as shown in Figure 5. From dissolution study, it was revealed that the synthesized cocrystals exhibited rapid drug release as compared to acyclovir. Percentage drug release of pure acyclovir after $30 \mathrm{~min}$ found to be $71.77 \%$ and that of cocrystals releases was found to be $83-88 \%$.

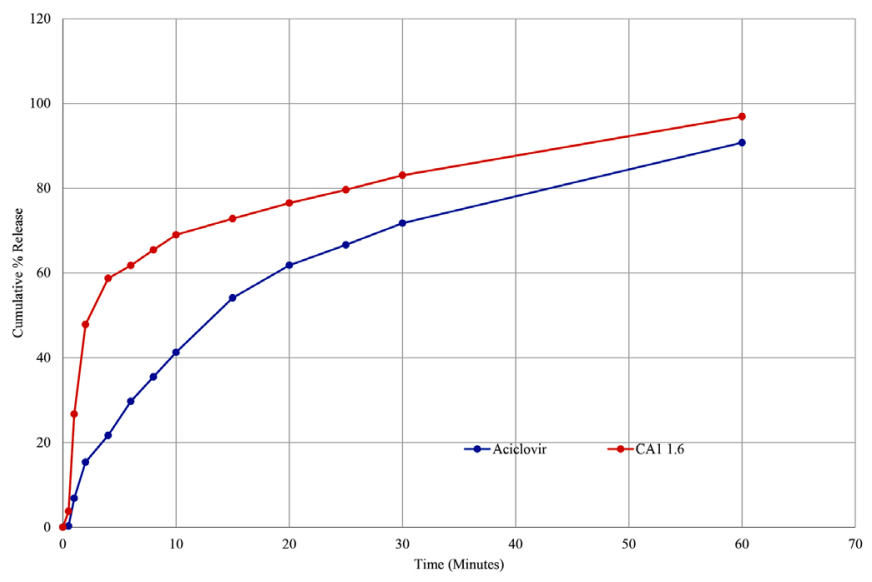

FIGURE 5 - Cumulative \% release of CA1 in comparison with acyclovir.

\section{CONCLUSION}

In our study, we used HSPs approach as a tool to predict the miscibility of cocrystal former and acyclovir. Selection of coformer was performed based on the prediction of HSPs. Cocrystals of acyclovir with improved solubility were developed using solvent evaporation method using water as a solvent. The ratio of drug to that of coformer was optimized by considering the number of theoretical hydrogen bond donor sites and hydrogen bond acceptor sites in acyclovir and cocrystal formers. The solid analysis was performed using Melting Point, Microscopic evaluation, IR, DSC and PXRD techniques. In vitro dissolution, assay was performed to check the dissolution of cocrystal initially. The study suggested the initial solubility of cocrystals was considerable higher as compared to pure drug. Hence synthesis of cocrystals of acyclovir can be considered as a promising approach for increasing the solubility.

\section{ACKNOWLEDGEMENTS}

The authors are grateful to Cadila Healthcare (Zydus), Ahmedabad for providing acyclovir as a gift sample.

\section{REFERENCES}

AAKERÖY, C.B.; DESPER, J.; FASULO, M.E. Improving success rate of hydrogen-bond driven synthesis of cocrystals. Cryst.Eng.Comm., v.8, n.8, p.586, 2006.

AAKERÖY, C.B., FASULO, M.E., DESPER, J. Cocrystal or salt: does it really matter? Mol. Pharm., v.4, n.3, p.317-322, 2007.

ALHALAWEH, A.; ALZGHOUL, A.; KAIALY, W. Data mining of solubility parameters for computational prediction of drug-excipient miscibility. Drug Develop. Ind. Pharm., v.40, n.7, p.904-909, 2014.

BALFOUR, H.H. Current management of varicella zoster virus infections. J. Med. Virol., v.41, n.S1, p.74-81, 1993.

BETHESDA, M.D. American hospital formulary service. AHFS Drug Information ${ }^{\circledR 97 . ~ A m . ~ S o c . ~ H e a l t h-S y s t . ~ P h a r m a c o l ., ~}$ v.440-449, p.2678-2680, 1997.

BIS, J.A.; VISHWESHWAR, P.; WEYNA, D.; ZAWOROTKO, M.J. Hierarchy of supramolecular synthons: persistent hydroxyl $\cdots$ pyridine hydrogen bonds in cocrystals that contain a cyano acceptor. Mol. Pharm., v.4, n.3, p.401-416, 2007.

BRUNI, G.; MAIETTA, M.; MAGGI, L.; MUSTARELLI, P.; FERRARA, C.; BERBENNI, V.; MILANESE, C.; GIRELlA, A.; MARINI, A. Preparation and physicochemical characterization of acyclovir cocrystals with improved dissolution properties. J. Pharm. Sci., v.102, n.11, p.4079-86, 2013.

DOILE, M.M.; FORTUNATO, K.A.; SCHMÜCKER, I.C.; SCHUCKO, S.K.; SILVA, M.A.S.; RODRIGUES, P.O. Physicochemical properties and dissolution studies of dexamethasone acetate- $\beta$-cyclodextrin inclusion complexes produced by different methods. AAPS PharmSciTech., v.9, n.1, p.314-321, 2008.

DUNITZ, J.D. Crystal and co-crystal: a second opinion. Cryst. Eng.Comm., v.5, n.91, p.506, 2003.

FEDORS, R.F. A method for estimating both the solubility parameters and molar volumes of liquids. Polym. Eng. Sci, v.14, n.2, p.147-154, 1974.

GREENHALGH, D.J.; WILLIAMS, A.C.; TIMMINS, P.; YORK, P. Solubility parameters as predictors of miscibility in solid dispersions. J. Pharm. Sci., v.88, n.11, p.1182-1190, 1999. 
GÜNER, A. The algorithmic calculations of solubility parameter for the determination of interactions in dextran/certain polar solvent systems. Eur. Polym. J., v.40, n.7, p.1587-1594, 2004.

JONES, W.; MOTHERWELL, W.D.S.; TRASK, A.V. Pharmaceutical cocrystals: an emerging approach to physical property enhancement. MRS Bull., v.31, n.11, p.875-879, 2006.

KADU, P.J.; KUSHARE, S.S.; THACKER, D.D.; GATTANI, S.G. Enhancement of oral bioavailability of atorvastatin calcium by self-emulsifying drug delivery systems (SEDDS). Pharm. Dev. Tech., v.16, n.1, p.65-74, 2011.

KARKI, S.; FRIŠČIĆ, T.; JONES, W.; MOTHERWELL, W.D.S. Screening for pharmaceutical cocrystal hydrates via neat and liquid-assisted grinding. Mol. Pharm., v.4, n.3, p.347-354, 2007.

KHAN, M.; ENKELMANN, V.; BRUNKLAUS, G. Crystal engineering of pharmaceutical co-crystals: application of methyl paraben as molecular hook. J. Am. Chem. Soc., v.132, n.14, p.5254-5263, 2010.

KRISTL, A.; SR`CI`C, S.; VRE`CER, F.; 'SU`STAR, B.; VOJNOVIC, D. Polymorphism and pseudopolymorphism: influencing the dissolution properties of the guanine derivative Acyclovir. Int. J. Pharm., v.139, p.231-235, 1996.

LUENGO, J.; ARÁNGUIZ, T.; SEPÚlVEDA, J.; HERNÁNDEZ, L.; VON PLESSING, C. Preliminary pharmacokinetic study of different preparations of Acyclovir with beta-cyclodextrin. J. Pharm. Sci., v.91, n.12, p.2593-2598, 2002.

LUTKER, K.M.; QUIÑONES, R.; XU, J.; RAMAMOORTHY, A.; MATZGER, A.J. Polymorphs and hydrates of acyclovir. J. Pharm. Sci., v.100, n.3, p.949-963, 2011.

MANIRUZZAMAN, M.; RANA, M.M.; BOATENG, J.S.; MITCHELL, J.C.; DOUROUMIS, D. Dissolution enhancement of poorly water-soluble APIs processed by hot-melt extrusion using hydrophilic polymers. Drug Dev. Ind. Pharm., v.39, n.2, p.218-227, 2013.

MASUDA, T.; YOSHIHASHI, Y.; YONEMOCHI, E.; FUJII, K.; UEKUSA, H.; TERADA, K. Cocrystallization and amorphization induced by drug - excipient interaction improves the physical properties of Acyclovir. Int. J. Pharm., v.422, n.1-2, p.160-169, 2012.
MOHAMMAD, M.A.; ALHALAWEH, A.; VELAGA, S.P. Hansen solubility parameter as a tool to predict cocrystal formation. Int. J. Pharm., v.407, n.1-2, p.63-71, 2011.

ÖZDEMIR, C.; GÜNER, A. Solubility profiles of poly(ethylene glycol)/solvent systems, I: Qualitative comparison of solubility parameter approaches. Eur. Pol. J., v.43, n.7, p.3068-3093, 2007.

PATEL, D.; SAWANT, K.K. Oral bioavailability enhancement of acyclovir by self-microemulsifying drug delivery systems (SMEDDS). Drug Dev. Ind. Pharm., v.33, n.12, p.1318-1326, 2007.

RAJURKAR, V.G.; GITE, R.D.; GHAWATE, V.B. Development of naproxen co crystal formation: an efficient approach to enhance aqueous sSolubility. Anal.. Chem. Lett., v.5, n.4, p.229-238, 2015.

ROSSEL, C.P.; CARREÑO, J.S.; BAEZA, M.R.; ALDERETE, J.B. Inclusion complex of the antiviral drug acyclovir with cyclodextrin in aqueous solution and in solid phase. Quim. Nova., v.23, n.6, p.749-752, 2000.

SACHAN, N.K.; PUSHKAR, S.; SOLANKI, S.S.; BHATERE, D.S. Enhancement of solubility of acyclovir by solid dispersion and inclusion complexation methods. W. Appl. Sci. J., v.11, n.7, p.857-864, 2010.

STAHLY, G.P. Diversity in single- and multiple-component crystals. The search for and prevalence of polymorphs and cocrystals. Cryst. Growth Des., v.7, n.6, p.1007-1026, 2007.

SUSANTAKUMAR, P.; GAUR, A.; SHARMA, P. Comparative pharmacokinetics, safety and tolerability evaluation of acyclovir ir $800 \mathrm{mg}$ tablet in healthy Indian adult volunteers under fasting and non-fasting conditions. J. Bioequiv. Availab., v.3, n.6, p128, 2011. DOI:10.4172/jbb.1000073.

TILSON, H.H.; ENGLE, C.R.; ANDREWS, E.B. Safety of acyclovir: A summary of the first 10 years' experience. $J$. Med. Virol., Suppl 1, p.67-73, 1993.

VAN KREVELEN, D.W. Properties of Polymers. 3. ed. Amsterdam:Elsevier Scientific Publ., 1990. p.212.

Received for publication on $10^{\text {th }}$ December 2014 Accepted for publication on $30^{\text {th }}$ September 2016 